\title{
Os nomes da história em perspectiva: Nietzsche, Emerson, Roux*
}

\author{
Arnaud Sorosina**
}

Resumo: em 1881-1882, o pensamento de Nietzsche o levou a elaborar seu conceito de vontade de potência e a ideia do perspectivismo, mesmo que o termo ainda não apareça sob sua pena. No presente artigo nós pretendemos mostrar que a ideia de pôr em perspectiva diversas idiossincrasias intelectuais está no coração mesmo da compreensão nietzschiana do perspectivismo, precisamente uma vez que ele reflete sobre a natureza da história no confronto com Emerson e sobre a natureza da evolução ao que descobre Wilhelm Roux.

Palavras-chave: perspectivismo, história, evolução, digestão, humanidade, futuro.

* Tradução de Saulo Krieger.

** Universidade Paris 1, CHSPM, Paris, França.

ORCID https://orcid.org/0000-0001-5472-0896

Correio eletrônico: arnaud.sorosina@yahoo.fr 
Sorosina, A.

\section{O perspectivismo, entre fatum e história}

As linhas que seguem pretendem mostrar que o perspectivismo pode ser visto como uma maneira de pensar e de reencontrar os nomes da história. É um aspecto espantosamente abandonado do pensamento de Nietzsche, mas ele permite que se forneça um critério de avaliação de perspectivas e de desembaraçamento das grandes linhas de uma genealogia do perspectivismo, cuja palavra e conceito aparecerão apenas tardiamente em sua obra. Seria equivocado, aqui como alhures, considerar que a palavra traz consigo a coisa. São bem outras considerações de Nietzsche que, sem convocar o vocabulário da perspectiva e do perspectivismo, entram, não obstante, de pleno direito entre as questões por eles implicadas: gaia ciência, humanidade do porvir, filosofia histórica, entre outras expressões do filósofo, podem - e com todo o rigor: devem - ser articuladas ao perspectivismo. Em todo caso é o que deveria permitir verificar o exame da relação que o filósofo entabula com os nomes da história.

Conhece-se a fórmula pítica com que termina a atividade filosófica de Nietzsche, início de 1889, no momento em que ele confia ao historiador Jakob Burckhardt: "no fundo, eu sou cada nome da história" (Carta de 4/5, de janeiro de 1889, KSB 8.578). Vista como o correlato dos perigos que apresenta o perspectivismo levado a seu paroxismo, tal asserção convida a lançar um esclarecimento histórico, axiológico e filosófico sobre o que significa "no fundo" essa multiplicidade dos nomes da história, e sobre o que implica o seu posicionamento em perspectiva. Poder-se-á então ler o que segue como uma espécie de comentário genealógico dessa declaração genialmente demencial, determinando, a partir dos póstumos de 1881, o lugar e a situação filosófica da Gaia ciência na obra de Nietzsche.

18 | Cad. Nietzsche, Guarulhos/Porto Seguro, v.42, n.3, p. 17-44, setembro/dezembro, 2021. 


\section{Da história à evolução: da história enquanto evolução}

Durante o ano de 1881, para dizer as coisas de maneira um tanto rápida, mas de modo algum de forma insolente, Nietzsche troca a concepção arqueológica das perspectivas históricas (que ele tinha adotado notadamente em Humano, demasiado humano, com a imagem dos Culturstufen $^{1}$ ) por uma concepção organicista da hierarquização de perspectivas. Não é por acaso que ele então começa a convocar o termo perspektivisch por volta do ano 1880 (NF/FP 1880, 6 [70], KSA 9.211; NF/FP 1881, 12 [33], KSA 9.581).

É então com o intuito de sustentar que o posicionamento em perspectiva dos nomes da história constitui o instrumento essencial da aculturação do bom europeu, que ele solicita outras perspectivas que não a sua a fim de curar do sentido histórico (entendido como saber sobre a história) por meio do sentido histórico (entendido como experiência da história) ${ }^{2}$. Em meio a essas outras perspectivas, existe a teoria biológica de Wilhelm Roux relativa à luta das partes no organismo ${ }^{3}$, da qual os $§ 118-119$ de A Gaia ciência fazem eco. Nietzsche vê aí a ocasião de inverter a concepção mística da história de Emerson, ao mesmo tempo conservando sua tese mais fundamental, segundo a qual "em cada ação se encontra a história mais abreviada de todo devir (NF/FP 1882, 17 [1] / KSA 9.666)". Essa tese faz chegar à ideia de que a história se identifica à biografia, o que nos convida a substituir o conhecimento histórico pelo vivido daquele que graças à história se torna quem ele é. Emerson escreve assim,

1 Cf. NF/FP 1876-1877, 23 [100, 129, 169, KSA 8.439/449/465] para as primeiras ocorrências do termo assim como da expressão Stufe (n) der Cultur nos Nachlass. Na obra publicada, cf. cf. MA/HH 111 e 614, KSA 2.112/348; VM/OS 223 e 323, KSA 2.477/511; WS/AS 16 e 186, KSA 2.550/633; M/A 96, 119 e 515, KSA 3.87/111/299. A última ocorrência, no § 157 de FW/GC (KSA 3.497), está no singular, o que não deve ser subestimado: o modelo geológico dos aluviões históricos cumpriu sua função para descrever o peso atávico do passado. Importa doravante pensar a força criadora da história.

2 Aqui ainda, são os romanos, e não os gregos, que ilustram essa potência de digestão, em particular em suas traduções dos autores estrangeiros (FW/GC 83, KSA 3.438).

3 W. Roux, Der Kampf der Theile im Organismus. Leipzig: Engelmann, 1881 [BN].

Cad. Nietzsche, Guarulhos/Porto Seguro, v.42, n.3, p. 17-44, setembro/dezembro, 2021.| 19 
Sorosina, A.

num fragmento copiado por Nietzsche num caderno de anotações relativo aos Versuche: "O instinto criador da alma se mostra no lucro que nós sabemos tirar da história: só há biografia. É preciso que cada qual reconheça a sua própria tarefa por inteiro. Esse lá e aqui desordenado, grosseiro e absurdo deve desaparecer e dar lugar ao hic et nunc (NF/FP 1882, 17 [5] / KSA 9.666)."

Nietzsche comenta na margem de seu exemplar de Emerson: "Absorva a fundo as situações da vida, as oportunidades de sua vida! Não basta ser uma individualidade! Isso significaria os incitar a se tornar limitados! Mas passar de uma individualidade a outra (NF/FP 1881, 13 [4]/ KSA 9, 618-619)!". Aderir à história significa assim se fazer múltiplo: o amor fati, aplicado à história, não é a resignação ao que se é, mas a adesão ao que se faz. Proteu seria a figura ética daquele que esposa o devir proteiforme, lá onde Argus designava o arqueólogo de cem olhos capazes de discernir os estratos fósseis da história cultural (VM/OS 223 KSA 2.477).

Desse ponto de vista, o que aparece ao exame desses textos póstumos de 1881, no momento em que Nietzsche lê, numa mão, A luta das partes no organismo, de Wilhelm Roux e, na outra, os Versuche, de Emerson, é a diferença entre duas maneiras de considerar o amor fati. Além do sentimento cósmico de adesão à totalidade do passado, que supõe aquiescer a cada acontecimento na medida em que é toda a cadeia do passado e do futuro que depende dele, Nietzsche parece ter exigências mais modestas para com o sentimento histórico de adesão ao passado, adesão que é total, mas que para tanto não implica a ingestão de todo o passado. Essa última só é possível pela intermediação de um pequeno número de elementos do passado, a saber, as grandes individualidades, aquelas em que o passado não é agregado ao acaso, como queria o modelo arqueológico dos Culturstufen ${ }^{4}$, mas digerido e totalizado em função de uma perspectiva, isto é, de certos instintos.

4. Ver de novo VM/OS 223 / KSA 2.477-478.

20 | Cad. Nietzsche, Guarulhos/Porto Seguro, v.42, n.3, p. 17-44, setembro/dezembro, 2021. 
Que essa assimilação, e a seleção que ela implica, sejam possíveis, tal se verificou por nossa época moderna, que de certa maneira põe fim ao reino da moralidade dos costumes, reino ao qual a civilização deve tudo, até a sua existência. Da pré-história da humanidade até a moral de Deus, foi a Moralität que governou, e facilmente se imagina que não era mesmo questão de interrogar a relação entre o indivíduo e a história: as ideias de idiossincrasia ou ainda de autonomia atreladas à de individualidade não tinham sentido algum. Quanto à época da moralidade dos costumes, onde o indivíduo não existe, a filosofia histórica pode então aplicar o arsenal da arqueologia da cultura elaborado por Humano, demasiado humano e Aurora, porque se trata da época prático-inerte da humanidade. Mas já durante essa longa pré-história, Nietzsche não ignora a possibilidade de que indivíduos capazes de inovar apareçam de maneira esporádica. E também é o caso de reter da história somente as individualidades mais ricas. De resto, a história universal encontra-se já latente na menor célula, mas sob forma fóssil. Seria perfeitamente inútil refazer a totalidade do caminho. Toda a questão está em transformar o prático-inerte em teórico-ativo, para utilizar em outro contexto o termo pelo qual Foucault sublinha Sartre ${ }^{5}$ : trata-se de revitalizar as formas fósseis conferindo a elas uma função num organismo vivo.

\section{O modelo funcional da digestão}

Mas como proceder? Nietzsche está de acordo com Emerson ao reconhecer que a profundidade da individualidade se mede pela sua potência de síntese: é preciso ser si mesmo uma perspectiva em devir que se nutre de perspectivas passadas. Mas não basta recapitular simplesmente em si esse passado e ser seu arauto. Emerson nada diz das modalidades sob as quais esse passado deve subsistir

5 Ver por exemplo M. Foucault, 2001, p. 527. Trata-se bem, de uma certa maneira, na ciência foucaultiana do arquivo da época, de converter o borrão em excitação, o que é igualmente a empresa de Nietzsche. 
Sorosina, A.

em nós, e é pouco eloquente sobre o que seria o caso de fazer do passado ou sobre o que seria o caso de selecionar do passado. E não por acaso: a Sobre-alma (Oversoul) do grande homem se deixa absorver pelo passado tomado como um todo. É nesse sentido que o transcendentalismo histórico de Emerson é perigoso, pois ele corre o risco de reconduzir ao misticismo pelo qual o indivíduo se reabsorve numa totalidade que lhe preexiste e da qual ele participa, o que termina por conduzir à negação do Querer-viver, de Schopenhauer, e não à afirmação do indivíduo pela digestão do passado. Nietzsche também corrige Emerson ao escrever: "Queres te tornar um olhar universal e justo? A ti é então necessário aquele que passou por muitas individualidades e das quais a última utiliza todas as precedentes enquanto funções (NF/FP 1881, 13 [5] / KSA 9, 619)".

Mudança de perspectiva essencial e radical: aqui é Wilhelm Roux que permite reinterpretar a concepção de Emerson introduzindo a ideia de que as perspectivas passadas das quais o indivíduo realiza a síntese orgânica são digeridas. Essas perspectivas são complexos de pulsões que é preciso instrumentalizar para convertê-los em órgãos de um novo indivíduo dotado de um novo objetivo orgânico. Roux defende explicitamente essa concepção organicista da função em seu livro intitulado A luta das partes no organismo, tendo-se aí uma alavanca conceitual que Nietzsche lhe toma de empréstimo durante o outono de 1881 para ler nesse sentido a história da cultura, como disso faz testemunho um texto póstumo que parafraseia uma passagem dessa obra e nela se inspira:

A célula é de início membro, mais do que indivíduo; no curso da evolução o indivíduo se complexifica cada vez mais e se torna cada vez mais ele próprio grupo de membros, sociedade. O livre ser humano forma por si mesmo um Estado, uma sociedade de indivíduos (...). O homem mais livre tem o maior sentimento de potência (...) o maior destacamento no combate necessário de suas diferentes forças, o combate relativamente maior dentro de si mesmo (etc.) (NF/FP 1881, 11 [130], KSA 9. 487-488). 
Ao se apropriar do conceito de função de Roux, Nietzsche ele próprio utiliza esse conceito como função numa nova matriz conceitual diferente da sua, sem de modo algum se sacrificar ao biologismo. O objetivo dessa instrumentalização do conceito de função está em naturalizar a concepção emersoniana da história para reinterpretá-la no quadro da "filosofia histórica", à medida que esta exige pensar a historicidade efetiva das relações de potência. Trata-se, então, por um lado, de afastar definitivamente a concepção mística da relação entre indivíduo e história, e, por outro lado, de se munir contra o reducionismo tendencial da teoria biológica da recapitulação, que se contenta com sustentar, com Von Baer e Haeckel, que a ontogênese individual recapitula a filogênse.

$\mathrm{O}$ que permite pensar o antagonismo das perspectivas de Emerson e de Roux é assim a história dos processos de assujeitamento pelos quais certas vontades de potência se tornam legisladoras dando às perspectivas do passado o sentido de uma função, segundo o processo que será descrito pela Genealogia da moral (II, 12), mas que se encontra antecipado pelos póstumos de 1881:

O sentimento de potência de início conquistador, em seguida dominador (organizante) - ele regula o que domestica para a sua própria conservação e para isso conserva aquilo mesmo que ele domestica. - A função igualmente é nascida do sentimento de potência, na luta com forças ainda mais fracas. A função se conserva ela própria pela coação e pela soberania que ela exerce sobre funções ainda mais baixas - no que ela é sustentada pela potência superior (NF/FP 1881, 11 [284], KSA 9.550)!

De momento, é a ideia mesma de uma hierarquia de perspectivas pulsionais que Nietzsche se esforça em estabelecer, no entrecruzamento da evolução biológica e da história cultural. A ideia de fazer funcionar as grandes perspectivas do passado como órgãos de nosso organismo atual recusa definitivamente a República schopenhaueriana de gênios que se projeta para fora da história. Com efeito, o imperativo consiste doravante em não "ver a nova 
Sorosina, A.

grandeza nem acima de si nem fora de si mesmo", mas em "fazer uma nova função de nós mesmos" (NF/FP 1881, 13 [19] / KSA 9, 621). Assim, Nietzsche utiliza Emerson e Roux como funções - a abordagem mostra-se em congruência com o que ela conceitualiza - para elaborar a sua própria concepção perspectivista da história.

Tal significa bem uma digestão, e não uma recusa: Nietzsche estabelece uma relação íntima com Emerson, a ponto de fazer desse antagonismo a ocasião de um ultrapassamento de si. Emerson serve de alimento na luta intestina que o próprio Nietzsche conduz contra ele. Eis por que ele chega a reconhecer que tal não seria fazer o elogio daquele, tamanha é a sua proximidade - magnetismo repulsivo do antípoda: "Por que as naturezas que me são opostas são as que me atraem mais intensamente? Elas me fazem sentir a necessidade da plenitude, elas têm seu lugar dentro de mim (NF/FP 13 [13] / KSA 9, 620)". Se então hierarquizar as perspectivas supõe passar "por muitas individualidades, a última delas utiliza todas as precedentes enquanto funções (NF/FP 1881, 13 [5], KSA 9.619)", aí se tem uma maneira bastante hábil de se dessolidarizar com Emerson, reapropriando-se de antigos amores: a Naturphilosophie do organismo de Goethe e a biologia dos organismos, que tinham entusiasmado o jovem Nietzsche leitor de Lange, a ponto de durante um tempo (em 1868) ele ter acalentado o projeto de uma tese sobre o conceito de organismo em Kant.

Por certo que não é questão de um voltar para trás. Simplesmente, Nietzsche se volta para uma concepção da evolução concorrente à de Darwin, e centrada não sobre o devir das espécies, mas sobre o da individualidade orgânica, a fim de ancorar sua concepção de história numa filosofia da evolução compreendida de maneira nova. De Wilhelm Roux, Nietzsche retém notadamente que o processo de assimilação orgânica não tem por objetivo somente "compensar as perdas", mas crescer até ser capaz de se reproduzir: ele "tende a 
uma compensação superabundante e quer se regenerar ${ }^{6 "}$, o que o leva a explorar o mais fraco e a competir com aqueles de uma força semelhante para assimilá-los, isto é, para torná-los idênticos a si mesmo. A assimilação é uma tirania ${ }^{7}$. $\mathrm{O}$ processo de assimilação é exatamente semelhante, ele opera sobre o plano intelectual ou biológico, uma vez que um e o outro são indistintamente axiológicos, e uma vez que o conhecimento mais não é do que uma certa relação entre as pulsões. Nenhum biologismo aqui, então: o perspectivismo visa a dinâmica evolucionista das pulsões como um processo de hierarquização axiológica, o que impede o rebaixamento da história dos valores à evolução biológica. Essa última fornece apenas uma matriz de interpretação para se pensar a historicidade dos processos de assujeitamento avaliativos. A assimilação não recopia ao reproduzir: ela imita, é certo, mas digere e transforma ao avaliar. Assimilar os sábios de modo algum reverte em imitá-los, mas em se apropriar deles para subordiná-los a seus próprios fins. O modelo orgânico da incorporação hierárquica por digestão assim transpõe e integra no tempo da biologia da evolução as três formas de história esboçadas na Segunda consideração extemporânea, na medida em que a assimilação das grandes perspectivas passadas supõe seu conhecimento antiquário e sua imitação monumental, mas a serviço da pulsão crítica que faz delas ao mesmo tempo rivais a ultrapassar: "O que se subordina, se metamorfoseia em função e renuncia quase que totalmente a numerosas forças originais e a liberdades primeiras e continua a viver assim - a escravidão é necessária à

6 FW/GC § 118 (KSA 3.389), que explora o conceito de função para aplicá-lo às células.

7 Nós resumimos o importante NF/FP 1881, 11 [134], KSA 9. 491-492. Sobre essa oposição entre conservação-adaptação de uma parte, e crescimento-exploração de outra parte, e seu papel na gênese do pensamento de vontade de potência, remetemos ao estudo tornado clássico de W. Müller-Lauter, 1978, p. 189-223. Cf. igualmente V. Gerhardt, 1996, p. 200 sq.; A. Orsucci, 1992, p. 192-202; M. Stingelin, 2003, p. 503-513. 
Sorosina, A.

formação dos organismos superiores, e mesmo à de castas $^{8 \%}$. Honrar os grandes do passado é então utilizá-los como funções a serviço de nossos objetivos, se é verdade que "[a] necessidade de 'honra' está em se querer reconhecido enquanto função (NF/FP 1881, 11 [134], KSA 9, 491-492).

\section{O modelo sanitário da excreção}

O grande indivíduo é assim um "sistema de vida" no sentido em que é composto de partes funcionais que são elas próprias sínteses orgânicas de pulsões, de modo que o indivíduo mais poderoso, aquele que recapitulará a história em si da maneira mais criadora, será aquele que se encontra dotado do mais alto grau de integração do múltiplo, feito uma boneca russa: "Quem tem mais força para rebaixar outro ao estado de sua função domina - mas os serviçais têm por sua vez seus próprios serviçais - seus perpétuos combates: a manutenção destes é até certo grau a condição de vida do conjunto. O conjunto por sua vez busca a sua vantagem e encontra adversários (NF/FP 1881, 11 [134] / KSA 9.491-492)". Essa concepção integrada da individualidade biológica por certo que não é a grande originalidade de Nietzsche: é um leitmotiv da época, que já havia atraído a atenção do jovem filólogo ao que, perigosamente desviado de seu sacerdócio não apenas por Schopenhauer (fins de 1865), mas também por $A$ história do materialismo de Friedrich Lange (em 1866), ele tinha encontrado expostos nesse último as concepções de organismo de Goethe e de Virchow.

Já original, em compensação, é a exploração do potencial heurístico dessa integração imbrincada para pensar o estatuto de não

8 NF/FP 1881, 11 [134], KSA 9, 491-492. Cf. FW/GC § 118, KSA 3.389: "Alegria e desejo coexistem no mais forte, que quer transformar algo em função sua; alegria e vontade de ser desejado, no mais fraco, que gostaria de tornar-se função". Ver também FW/GC, § 119, KSA 3.473: "Vejo em muitas pessoas uma força e uma vontade extremas de serem função; (...) Tais naturezas se conservam melhor quando se aninham num outro organismo (...)."

26 | Cad. Nietzsche, Guarulhos/Porto Seguro, v.42, n.3, p. 17-44, setembro/dezembro, 2021. 
importa qual perspectiva na história dos valores. Na integração de boneca russa da individualidade celular, são na realidade os abismos do passado histórico que Nietzsche encontra. $\mathrm{O}$ perspectivismo não encontrou ainda o seu nome, mas é bem dele que se trata com a integração dos valores passados em função de uma perspectiva de conjunto determinada igualmente por valores. $\mathrm{O}$ crescimento orgânico tem por objetivo a extensão de uma escala de valores. A "vontade de potência" é o nome dado a esse crescimento, uma vez que se encontra deslocada sobre o plano dos valores a problemática do crescimento das partes orgânicas, que os evolucionistas heterodoxos opõem então à vulgata darwiniana.

A ampliação da perspectiva, portanto, não significa que ela dá a ver mais coisas, mesmo que seja efetivamente o caso: antes de tudo, trata-se de vê-las melhor. O espectro estético da percepção e o espectro axiológico da avaliação se enriquecem com as perspectivas do passado, de modo que a rede que elas lançam sobre a realidade se densifica cada vez mais. Por outro lado, o organismo superior produz organismos biológicos parecidos com ele ${ }^{9}$, ações e obras dignas dele - essas últimas tendo vocação para durar o máximo de tempo e para servir de modelos perenes para outros organismos. Com esse fim, um princípio de economia leva esse organismo a esgotar o potencial nutritivo desses alimentos e a excretar o que não pode mais ser digerido:

Todo corpo desassimila sem cessar, ele elimina o que no ser assimilado se mantém por si mesmo inutilizável: o que o homem despreza, o que lhe inspira aversão, o que ele denomina como mau são os excrementos [excremente]. Mas sua "razão" ignorante não raro lhe designa como mau o que lhe falta, o que lhe embaraça, o outro, o inimigo, e assim ele confunde o inutilizável com o que é difícil de adquirir, difícil de vencer, difícil de incorporar. Uma vez que ele "comunica" a outros, "compartilha", se mostra "desinteressado"

9 É a razão pela qual Nietzsche queria que a reprodução fosse "um privilégio" atribuído unicamente aos espíritos superiores (NF/FP 1881, 14 [16], KSA 9.627). 
Sorosina, A.

- tudo isso mais não é talvez que a eliminação de suas inutilizáveis fezes [faeces] de que é preciso se livrar para não sofrer por causa delas. Ele sabe que esse adubo é útil ao campo estrangeiro e se faz uma virtude de sua "liberalidade". - O "amor" é o sentimento para a propriedade ou para o que nós desejamos enquanto propriedade ${ }^{10}$.

Do que esse texto dá testemunho ainda é da naturalização da "sobre-alma" cara à Emerson, Ouversoul, esta capaz de absorver em si todo o espiritual. Essa concepção filosófica da função excremencial nos afasta resolutamente - com toda a picância da desmistificação genealógica, que conduz a idealidade a um húmus escabroso - do lirismo emersoniano. Além disso, Nietzsche procede, aqui, contra a sua antiga atração por Schopenhauer, a uma historização da condição pretensamente "suprahistórica" do gênio: "Não ter a nova grandeza nem acima nem fora de si mesmo, mas fazer disso uma nova função de nós mesmos. / Nós somos o oceano no qual é preciso que venham desaguar todos os rios da grandeza ${ }^{11}$."

Faltava por certo a Emerson (e sem dúvida igualmente a Schopenhauer) a formação científica ${ }^{12}$ que o teria disposto a dar toda a sua dimensão a seu sentido histórico ainda tingido de misticismo. Nietzsche, por sua vez, assume o entusiasmo exaltado pela grandeza e lembra que o que é alimento para um não vai ser mais do que o excremento de um indivíduo superior a ele. Deve-se observar, enfim, que a aversão ${ }^{13}$ que o indivíduo superior pode experimentar por suas próprias fezes não se põe em sentido contrário ao amor fati: o amor

10 NF/FP 1881, 11 [134], KSA 9. 491-492. Ver igualmente NF/FP 1881, 14 [13], KSA 9.626 e NF/ FP 1881, 11 [53], KSA 9. 460, que prepara FW/GC § 59, KSA 3.422.

11 Anotações sobre Emerson, NF/FP 1881, 13 [19], KSA 9.631.

12 Ver as cartas de Nietzsche a Overbeck de 24 de dezembro de 1883 e 22 de dezembro de 1884 .

13 Há diversos textos em que Nietzsche afirma que o desgosto é um componente irredutível do pathos da distância e assim de toda hierarquia de valor; isso explica que "a fraqueza do desgosto caracteriza a cultura industrial e utilitária” (NF/FP 1881, 11 [50], KSA 9.459), como é o caso particular no social darwinismo de Spencer (NF/FP 1881, 11 [20, 37, 40, 43, 73, 98, 343], KSA 9.450, 54, 55, 57, 69, $76,9.574$ ), esse último pressupondo sempre a igualdade dos homens (NF/FP 1879-1880, 1 [98]).

28 | Cad. Nietzsche, Guarulhos/Porto Seguro, v.42, n.3, p. 17-44, setembro/dezembro, 2021. 
do fatum não significa que é necessário tudo ingerir, mas que seja reconhecida a hierarquia dos seres e $o$ valor que eles podem abranger em função do grau de individuação e de cultura do organismo que os assimila. $\mathrm{O}$ adubo do grande indivíduo pode fertilizar o campo do inculto.

Passar por muitas individualidades é, então, tornado possível pela excreção, que Nietzsche parece considerar a um só tempo como expulsão do que não é assimilável mas também, o que é mais espantoso, como a capacidade de se desfazer do que já foi assimilado, mas cujo potencial nutritivo e energético se esgotou. $\mathrm{O}$ leitor prudente só mensurará o gesto irreverente e altivo que Nietzsche sugere aqui no momento de comunicar e de partilhar seus pensamentos com ele, e isso tão-somente para se desembaraçar deles ${ }^{14}: 0$ que é ruminado acaba por ser excretado. Contra a idealidade das meditações, Nietzsche nos submete o produto de suas ruminações, mas igualmente sua digestão. Ele inventa assim uma figura bastante inesperada do leitor, que deverá antes de mais nada ser humildemente iniciado na coprofagia. Sem dúvida que não é desejável passar a vida como leitor e filólogo, isto é, ter-se-á compreendido, como um parasita fecalfilíaco! O aforismo é assim a expressão de um ponto de vista que, no momento de encontrar sua fórmula, é já, de uma certa maneira, ultrapassado simples momento da busca de uma individualidade mais profunda, de uma outra máscara.

A concepção histórica da identidade que deriva daí é o exato oposto do gnôthi seauton platônico. No Protágoras (312b-314b), Sócrates pretende firmemente estabelecer que, à diferença dos alimentos, os conhecimentos não podem se armazenar em si a seu critério, mas são assimilados de uma vez por todas, dando um quê particular a nosso espírito e a nosso caráter, do qual não poderemos

14 "Quanto ao que são meus "pensamentos", pouco me importa tê-los, e sim deles me desembaraçar, uma vez que desembaraçar-me deles se torna sempre excessivamente difícil!" (Carta a Köselitz de 29 janeiro de 1882 / KSB 6. 161). Essa confissão encontrará sua expressão pública em FW/GC § 93. 
Sorosina, A.

nos desfazer na sequência. A concepção agonística e hierarquizada da individuação que Nietzsche defende se encontra diametralmente oposta a essa ideia:

O homem mais livre tem o maior sentimento de potência, o maior saber para além de si mesmo; ele tem o maior destacamento no combate necessário de suas forças, a independência relativamente maior de suas diferentes forças, o combate relativamente maior dentro de si mesmo; ele é o mais dividido, o mais rico em variações, o mais apto a viver por mais tempo, o mais fecundo em cobiças e em recursos para se nutrir, o que mais sabe eliminar de si mesmo e se renovar (NF/FP 1881, 11 [130] / KSA 9.488).

O homem mais livre é então a um só tempo o mais individual e o mais multicor: é que o "eu" - "cruel até a mutilação de si mesmo, não desmascarado (...) tentador que vive do sangue de almas estrangeiras ${ }^{15 "}$ - não tem nenhuma consistência ontológica previamente definida: de início ele não é mais que uma matriz de pulsões hereditárias e desordenadas, um "passivo" pulsional que pode bem fazer sonhar com o "isso" da segunda tópica freudiana. O que interessa a Nietzsche é a constituição de um "si" que - alternativa à reconciliação hegeliana tanto quanto à síntese eclética - integra as perspectivas mais múltiplas e as mais opostas. Ele também prepara a lista de tarefas a realizar uma vez que nos livramos da proposição emersoniana dessas escórias místicas: "[T]entativas de mudar, começando por romper com nossos hábitos (por exemplo, regime) / Apoiar-se intelectualmente sobre adversários eventuais, tentar viver em sua atmosfera / viajar, em todos os sentidos do termo (...). / Repousar temporariamente de suas experiências, digeri-las / (...) Tentativas de criar um ideal e ulteriormente de vivê-lo (NF/FP 1881, 13 [20], KSA 9.621)." A realidade do "si" não é, contudo, fictícia: "Que uma coisa se resolva numa soma de relações nada prova contra a sua realidade (NF/FP 188113 [11], KSA 9. 620)". Simplesmente,

15 Anotações a Emerson, NF/FP 1881, 13 [21] / KSA 9.622.

30 | Cad. Nietzsche, Guarulhos/Porto Seguro, v.42, n.3, p. 17-44, setembro/dezembro, 2021. 
o caráter se identifica ao organismo ${ }^{16}$, que é ele próprio um conjunto de relações cuja orientação e hierarquia são determinadas por seu grau de individuação. A intensidade da individualidade se mede assim por sua potência de digestão, essa última consistindo em fazer o si com o não eu ${ }^{17}$.

\section{Da evolução à história: perspectivas e heráldica}

É bastante compreensível que essa filiação filosófico-científica, que liga Nietzsche a Emerson e Roux, ao mesmo tempo que deles se emancipa, participa de uma ambição heráldica, que reúne sob um mesmo estandarte os irmãos de sangue que os caprichos do gigante Acaso disseminaram na história: "Eu quero ter minha heráldica [Heraldik] e conhecer toda a nobre genealogia [Stammbaum] de meu espírito - é somente a história [Historie] que a dá. Sem essa última não somos mais do que efêmeros mosquitos e canalhas: nossas lembranças remontarão no máximo a nosso avô - ali se detém o mundo ${ }^{18}$."

É que Nietzsche não se considera como um ponto de chegada da história que o precede - a história até ali não foi mais do que o reino do caos e do acaso, segundo um diagnóstico schopenhaueriano que ele retém ainda em Para além de bem e mal (\$ 203). A heráldica se constitui por uma seleção retrospectiva: a Züchtung não girou unicamente para o futuro! Compreende-se que seja necessário abandonar essa ficção de esteta-metafísico que foi a República de gênios: esta não existe no céu das Ideias, mas se conquista por uma lenta maturação. Ela assume então a forma da comunidade dos espíritos livres. Se Nietzsche se considera como um "destino", é no sentido em que ele transformou esse acaso em necessidade: ofatum

16 "Caractere = organismo" (NF/FP 1881, 13 [18] / KSA 9.621).

17 É nesse sentido que Nietzsche pode escrever, anotando sempre sobre Emerson: "O que apreendi até este dia (15 de outubro de 1881)? A sair de todas as situações de modo salutar para mim mesmo sem ter de recorrer aos outros" (NF/FP 1881, 13 [16], KSA 9.621).

18 NF/FP 1881, 15 [70], KSA 9.658. Cap. Za/ZA, III, “De velhas e novas tábuas” § 11, KSA 4.254. 
Sorosina, A.

designa uma tal potência transformadora e legisladora, assim como a disposição em fazer corpo com a necessidade cósmica, necessidade da luz da qual o tempo humano da história aparece como o fruto do acaso. Se Nietzsche não podia ser de outro modo, nem aparecer num outro instante, é que ele é um acaso necessário: acaso histórico, no sentido em que sua existência e sua tarefa não são dedutíveis de leis do desenvolvimento histórico; necessidade ontológica, no sentido de que ele não pode ser diferente do que é.

É porque confundem as duas ordens, a do tempo histórico e a do fatum cósmico, que "os tiranos de todos os tipos (...) de moto próprio fazem violência à história a fim de que ela apareça como uma preparação a conduzir por graus à sua pessoa ${ }^{19}$. A nobreza genealógica não reside então na carotagem de um material nobre: não importa quem possa inventar para si um brasão e uma linhagem. A nobreza é a capacidade de fazer de todas as coisas, mesmo aparentemente as mais estéreis, um fertilizante para o seu próprio terreno. Isso é exigido pelo eterno retorno: não há excremento em si, porque o adubo fertiliza. Um anti-Parmênides evidentemente não crê na Ideia da Lama $^{20}$. Por isso Nietzsche sabe também pagar a sua dívida e poupar o tempo reservado à admiração para o que via de regra ele execra: Platão, o cristianismo, a modernidade etc. É aqui que se faz a partida entre o sentido da hierarquia ainda verde e o espírito livre acabado: "Em tudo o que se esquiva e em tudo o que nega trai-se uma falta de fecundidade: no fundo, se fôssemos terra boa, não deixaríamos nada perecer sem aproveitamento, e em toda coisa, todo acontecimento e todo homem veríamos um fertilizante, uma gota de chuva e um raio de sol bem-vindos (VM/OS $§ 332$, KSA 3.515)". Esse pathos heráldico é acompanhado pelo sentimento de orgulho (Stolz) por pertencer a uma grande casa - peça a acrescentar ao dossiê relativo à

19 VM/OS 307, KSA 2.504.

20 Cf. desse ponto de vista Platão, Parmênides 130c, e Za/ZA III, "De velhas e novas tábuas" § 14, KSA 4.257.

32 | Cad. Nietzsche, Guarulhos/Porto Seguro, v.42, n.3, p. 17-44, setembro/dezembro, 2021. 
ética historiadora, isto é, ao ethos do historiador. O pathos do orgulho é antagônico à busca da glória. De fato, à época de maturação da Segunda consideração extemporânea, a filologia do futuro ainda estava voltada para a irradiação gloriosa de sua aura. É ainda a glória que motiva então o criador, em que se juntam conhecimento e potência de renovação da civilização (NF/FP 1872-1873 19 [172], KSA 7.472). Disso confere testemunho a condição que é então feita aos filósofos: "Os filósofos são a classe mais distinta entre os grandes de espírito. Eles não têm público, é-lhes necessária a glória. Para comunicar suas maiores alegrias, é-lhes necessária a prova: nisso eles são mais infelizes que os artistas (NF/FP 18721873, 19 [168], KSA 7.471)."

Em 1881, Nietzsche passa a opor a essa busca da glória o sentimento soberano do orgulho que não carece de nada, mas se impregna do passado que ele tem a tarefa de representar e de honrar.

Por um lado, isso supõe integrar em si a grandeza passada, compreendendo aqui a prova de hostilidade para consigo, de modo a que o orgulho venha enobrecer "tudo o que existe de humano", o que distingue muito claramente o historiador orgulhoso, que se eleva assim até o amor fati, de um fatalista resignado: "Quando eu falo de Platão, de Pascal, de Spinoza e de Goethe, eu sei que seu sangue corre em minhas veias - eu fico orgulhoso [stolz] uma vez que digo a verdade quanto a isso - a família é suficientemente boa para não ter necessidade de afabular ou de dissimular; e é assim que eu me comporto com relação a tudo o que tem sido, eu sou orgulhoso do que há de humano e orgulhoso precisamente de uma incondicional veracidade (NF/FP 1881, 12 [52], KSA, 9.585)."

Por outro lado, esse orgulho distingue toto coelo o filósofo historiador amoroso do fatum de todos os seus predecessores, de modo que o orgulho constitui o pathos da distância por excelência, à medida que ele significa que o presente está grávido de todo o passado assimilado para dar nascimento ao futuro, lá onde os homens 
Sorosina, A.

do passado, buscando a glória, ocultavam sem vergonha sua história para dar a ilusão de criar a partir do nada: "Na antiquidade todo homem superior transportava a glória [Ruhme] - o que vinha de que cada qual pensava inaugurar a humanidade a partir de si mesmo e só teria sabido buscar espaço e duração para si projetando-se na posteridade enquanto ator de tragédia a desempenhar seu papel sobre a cena eterna (NF/FP 1881, 15 [17], KSA 9.642)".

Pelo contrário, acrescenta Nietzsche logo em seguida, o orgulho consiste em saber de onde se vem ${ }^{21}$ - "sim, eu sei de onde provenho 22 !" - para reunir o passado em si e concentrá-lo de modo a experimentar um acréscimo de força fisiológica degustando a seiva de sua árvore genealógica. Essa operação corresponde muito precisamente à empresa realizada pelo sentido histórico tornado grande saúde:

Meu orgulho [Stolz], ao contrário, consiste em que "eu conheço minha proveniência [Herkunft]" - é por isso que eu não tenho necessidade alguma de glória. Em tudo isso que podia comover Zoroastro, Moisés, Maomé, Jesus, Platão, Brutus, Spinoza, Mirabeau, também eu então ali vivia, e para muitas coisas é em mim que vem à lume o que demandou alguns milênios para passar do estágio embrionário àquele de plena maturidade. Nós somos os primeiros aristocratas na história do espírito - é a partir de agora que se inicia o sentido histórico [historische Sinn] (NF/FP 1881, 12 [52], KSA 9.585).

Se a aristocracia espiritual caracteriza o novo sentido histórico, é que ela permite aceder autenticamente ao sentimento cósmico do $\mathrm{Si}$, sentimento fundado não sobre uma experiência mística, em que se alternam o sentimento de ser Deus e o de ser um verme, mas sobre o "sentimento de si" que se acompanha de modéstia (o que eu sou, eu o devo aos grandes nomes da história que me precedem) e de orgulho

21 Comparar NF/FP 1881, 12 [79], KSA 9. 590: "Eu tenho uma proveniência [Herkunft] - é o orgulho [Stolz], oposto à cupido gloriae. Não me é estranho, que Zaratustra --- ".

22 FW/GC “piada, ardil e vingança”, § 29, KSA 3.367.

34 | Cad. Nietzsche, Guarulhos/Porto Seguro, v.42, n.3, p. 17-44, setembro/dezembro, 2021. 
(eu sou o herdeiro desses nomes) ${ }^{23}$. $\mathrm{O}$ aristocrata adota um regime específico que lhe ordena "não viver entre homens com os quais não se possa comparar, seja porque a modéstia, seja porque o orgulho o impede. Esse regime é o regime que se impõem os aristocratas. Fatum, eis aí uma ideia inspiradora para aquele que compreende que faz parte disso ${ }^{24}$."

Sabe-se que o sentimento cósmico de si se identifica ao amor fati e ao sentimento correlativo de mais não ser que um fragmento de fatum que acompanhará eternamente esse sentimento. Lá onde a glória testemunha uma insuficiência e uma incompletude no sentimento de si, o orgulho permite aceder a uma profundidade infinita da Erlebnis que eterniza o instante decisivo e a totalidade do passado que ele carrega consigo, e por consequência o fatum ele mesmo. $\mathrm{O}$ orgulho permite aceder assim a "uma bem outra eternização" - a glória progride numa falsa dimensão. É-nos necessário aí projetar a eterna profundidade, a eterna propensão à repetição (NF/FP 1881, 12 [192], KSA 9.609)." O sentimento de si se orgulha de tudo o que é humano, e eternizar o passado aristocrático do qual ele provém é, pois, o sentimento histórico fecundado pelo sentimento de humanidade vindoura do qual deve nascer o amor fati. Por conseguinte, não surpreende que o instrumento de cultivo destinado a formar um tal sentimento seja o pensamento do eterno retorno.

\section{A autossuperação do sentido histórico: a humanidade do porvir}

Nietzsche estanca no limiar de um tal sentimento em $A$ gaia ciência: sua plena eflorescência está ainda por vir. O § 337 anuncia assim uma conversão do sentido histórico que acompanha

23 NF/FP 1884, 26 [442] intitulado: "O místico alemão". A aspiração a sair de si caracteriza a aspiração mística fraca, lá onde "os poderosos, os fortes querem formar e não ter nada mais de estrangeiro em seu redor!" (NF/FP 1883, 7 [145], KSA 10.291).

24 NF/FP 1884, 26 [442].

Cad. Nietzsche, Guarulhos/Porto Seguro, v.42, n.3, p. 17-44, setembro/dezembro, 2021.| 35 
Sorosina, A.

a parábola do eterno retorno $(\$ 341)$ e a entrada em cena de Zaratustra (\$342). Trata-se para Nietzsche de definir o lugar e a tarefa do homem moderno considerando o sentido histórico como uma doença que compreende em si mesmo suas próprias virtudes medicinais: produzido pela "diminuição de todos os sentimentos antigos", o sentimento histórico é antes de mais nada a expressão da angústia (Noth). Mas o aprofundamento do pessimismo cura a angústia inconsciente de si dos homens modernos pela angústia consciente e voluntária ${ }^{25}$. O sentido histórico é, desse ponto de vista, um "germe" à espera de seu florescimento, germe este que o inovador, no $\$ 106$ da Gaia ciência, queria converter em árvore do porvir, tornando-se irrefutável pela "arte dos sons". Sabe-se que essa "arte dos sons" que vai converter esse germe em árvore mais não é do que a palavra de Zaratustra, o que ensina o eterno retorno e o além-do-homem. O "sentimento da humanidade do porvir" estará então além da humanidade tal como ela foi apreendida até o presente. Para formar, "elo e elo ${ }^{266 ،}$, a cadeia de ouro que formará esse sentimento, é preciso chegar a preliminarmente recapitular a história em si para aderir a ela, por certo, mas reivindicando para si uma árvore genealógica diferente daquela que põe em evidência a história dita universal, isto é, a história das massas onde triunfaram os valores não nobres.

É num diálogo ininterrupto com Emerson que Nietzsche elabora assim seu pensamento mais íntimo e mais profundo: o aprofundamento do sentido histórico converterá a angústia em Heiterkeit. Reviver em si a história é uma etapa incontornável dessa incorporação: é a realização ética da filosofia histórica. De sua parte, Emerson fazia disso um instrumento de elevação e de educação: “O mundo existe para a educação de cada homem. Não há na história da época, estado da sociedade ou modo de ação que não encontre em sua vida algo

25 Assim como para tal convida o § 48 de FW/GC, KSA3.414.

26 Para essas citações, cf. FW/GC § 337, KSA 3.564.

36 | Cad. Nietzsche, Guarulhos/Porto Seguro, v.42, n.3, p. 17-44, setembro/dezembro, 2021. 
que lhe corresponda. De maneira maravilhosa, cada coisa tende a se abreviar e a expressar sua virtude em benefício do homem. Ele deveria se aperceber de que pode viver toda a história em sua própria pessoa ${ }^{27}$ ".

Essa lição de Emerson foi retida e meditada por Nietzsche: a história deve deixar de ser compreendida e apreendida do exterior como um conjunto de topoi, sinal dos tempos em que se busca, pelo viés do passado, evadir-se da grisalha do presente. Porém isso mais não é que um sentido histórico pobre e frio, um "golpe de congelamento" numa modernidade que aparece como "um doente melancólico que, para esquecer de seu presente, escreve a história de sua juventude (FW/GC § 337, KSA 3.564)." Isso quanto ao lugar da modernidade. Quanto à tarefa, a reavaliação de todos os valores do qual será questão nos anos 1887-1888, ela consiste antes de mais nada e antes de tudo em reavaliar o sentido histórico, numa conversão de seu "sentido", precisamente e em virtude de um movimento de recuperação orgânica que confere uma nova coloração a esse sentimento histórico novo:

[Q]uem sabe sentir a história dos homens em seu conjunto como sua própria história experimenta, numa universalização formidável, toda a aflição do doente que pensa na saúde (...); mas suportar, saber suportar essa formidável soma de aflição de todo tipo e se manter entretanto o herói que (...) saúda a aurora e sua felicidade em homem que tem, diante de si e atrás de si, um horizonte de milênios, herdeiro de toda aristocracia de todo espírito passado, e herdeiro a que incumbem obrigações, em homem o mais nobre de todos os nobres antigos e ao mesmo tempo primogênito de uma nobreza nova, tal como não viveu e não sonhou ainda época alguma (...): deter enfim tudo isso no seio de uma única alma e condensá-lo num único sentimento: - eis o que deveria produzir uma felicidade que o homem ainda não conheceu até o presente, - uma felicidade de deus (...)! Esse sentimento divino se chamaria então - humanidade (FW/GC § 337, KSA 3.564).

27 Essais II, trad. Ch. Fournier. Paris: Michel Houdiard, 2005, p. 23.

Cad. Nietzsche, Guarulhos/Porto Seguro, v.42, n.3, p. 17-44, setembro/dezembro, 2021.| 37 
Nietzsche destitui assim o sentido histórico dos filólogos pretensamente objetivos, na medida em que é desprovido de pathos, de simpatia real pelo passado, mas igualmente destitui as robinsonadas voluntaristas daqueles que, como Wagner ou Schopenhauer (e talvez ele próprio na época da metafísica de $\left.\operatorname{artista}^{28}\right)$, pretendem se livrar da história para criar a partir de uma "intuição estética", inspirados por uma piedade jorrada do coração do Querer. É notável, com efeito, que Nietzsche se informa sobre nossa compaixão para com o passado e convida a reeducar nosso pathos histórico a fim de evitar estas duas ciladas, a saber, o conhecimento histórico em que o passado é tomado pelos gelos dos saberes científicos, e a tábula rasa que descura desse conhecimento. Discretas, e entretanto essenciais, são as indicações que Nietzsche nos deixa, que dão testemunho de uma atenção aumentada à importância do pathos histórico cuja natureza e intensidade são determinantes para a transformação ética que deve conduzir da febre história à gaia ciência daquele que herda da "aristocracia de todo o espírito passado":

Não tendes compaixão [Mitleiden] pelo passado? Não vedes como ele está à mercê da graça e depende dela, do espírito e da equidade de cada geração, como uma pobre mulherzinha? Não é que a todo instante algum gênio maligno ameaça surgir, gênio que nos obrigaria a desconhecer completamente o passado, que tornaria surdas nossas orelhas e mesmo nos poria chicote na mão para o maltratar? $O$ passado não tem a mesma sorte que a música, a melhor música de que dispomos? Um novo e perverso

28 Pode-se interpretar nesse sentido os textos póstumos em que Nietzsche assume a contradição entre seu ontem e seu hoje: "Eu assumo a liberdade de me esquecer. Por que não contradizer?" (NF/ FP 1881, 12 [127], KSA 9. 598). "Tu contradizes hoje o que ensinaste ontem -. Em compensação ontem não é hoje, diz Zaratustra." (NF/FP 1881, 12 [128], KSA 9. 598). "Tu és duro com relação a teu primeiro ideal e dos seres com que estás ligado. - De fato, eu passei por cima deles para me questionar sobre um ideal superior, como a me elevar sobre os degraus de uma escala - onde, assentado, pensava ele, eu tomaria repouso." (NF/FP 1881, 12 [130], KSA 9.599). Comparar Emerson, Essais II, op. cit., p. 146-147: "um homem bem considerado abraça e contém as naturezas particulares de todos os homens. (...) Nós temos esse homem, e somos levados mais longe. Uma a uma, esvaziamos todas as cisternas e, engrandecidos por todas essas reservas, desejamos um alimento melhor e mais abundante. Ainda não nasceu o homem que poderá nos nutrir eternamente. (...) É uma alma única que anima todos os homens."

38 | Cad. Nietzsche, Guarulhos/Porto Seguro, v.42, n.3, p. 17-44, setembro/dezembro, 2021. 
Orfeu, que a cada hora poderia engendrar, estaria talvez em condições de nos persuadir por suas tonalidades de que nós ainda não teríamos nenhuma música e que o melhor a fazer seria evitar tudo o que assim se denominava até então (NF/FP 1881, 15 [51], KSA 9.651-652).

Não haverá mal algum em reconhecer por detrás das seduções de Orfeu os encantos de Wagner. A “piedade”, por sua vez, é uma alusão mordente a Schopenhauer, que não tinha a menor inclinação para a história: ela é essa forma de piedade que Nietzsche autoriza, em Para além de bem e mal, entre pares nobres ${ }^{29}$, e é uma piedade que compreende ademais os sofrimentos dos grandes homens da história como sendo a mola essencial de sua genial criatividade.

De modo que essa piedade pelo passado deve chegar à compreensão vivida dos processos de assimilação que permitem aos gênios sintetizar o passado. Eis aí o pathos essencial de uma nova forma de história monumental que se dá os meios de reproduzir as grandes criações por outra forma que não a consideração dos "efeitos em si”, conforme convidava a Segunda consideração extemporânea, mas passando a considerar a cadeia de ouro das causas e os instantes decisivos em que os indivíduos poderosos são capazes da grande síntese. Eis por que a compreensão dos sofrimentos do criador, a montante, alcança aquela de suas maiores felicidades, nas criações que elas tornam possível, a jusante. A simpatia é então um processo de incorporação que permite sobrepujar o sofrimento compartilhado detectando as modalidades de sua sublimação, até a sua conversão em alegria.

29 Cf. JGB/BM, § 225, KSA 5.160 in fine: "E a nossa compaixão - não percebem a quem se dirige a nossa compaixão contrária, quando se defende da sua compaixão como o pior dos ensombrecimentos e debilidades? Compaixão contra compaixão!". 
Sorosina, A.

Sem dúvida que essa conversão da ética da compaixão em ética do júbilo, que Zaratustra chamará de seus votos ${ }^{30}$, é comandada por esse sentimento histórico novo. Ao refazer assim toda a história dos sofrimentos e das felicidades do gênio, um tal historiador se torna efetivamente o herdeiro de toda a nobreza passada, obrigado para com esse passado na medida em que esse passado lhe intima a se tornar digno dele. Se esse historiador do porvir é o "primogênito de uma nobreza nova", se ele rompe a história humana em duas partes, é em virtude de seu estatuto ambivalente, na medida em que, à diferença dos nobres antigos, ele cria chamando à vida, a partir da diminuição dos antigos sentimentos, a totalidade de forças criadoras que anteriormente faziam o seu vigor ${ }^{31}$. Diferentemente dos antigos nobres, ele conhece até o fim sua proveniência e dela extrai a potência de criações novas, alquimista que faz a história a partir da história tal como ela é feita. O eterno retorno não é mais do que essa reunião entre o passado e o futuro que desorienta a flecha do tempo e convida a pensar de novo nossa relação com a história.

\section{Conclusão}

A gaia ciência é, então, se não o acabamento, pelo menos um primeiro ponto de fuga da filosofia histórica. Na medida em que ela traz a potência de cura e a conquista da Heiterkeit a partir do mais profundo sentimento de angústia ${ }^{32}$, a obra testemunha a cura do sentido histórico por meio do próprio sentido histórico. Com efeito, foi o aprofundamento do sentido histórico que permitiu a Nietzsche

30 "Desde que existem homens, o homem se alegrou muito pouco: apenas isso, meus irmãos, é nosso pecado original! / Se aprendemos a nos alegrar melhor, melhor desaprendemos de causar dor nos outros e planejar dores. / Por isso lavo a minha mão que ajudou um sofredor" (Za/ZA II, "Dos compassivos", v. 12-14, KSA 4.113).

31 Cf. Extratos de Emerson, NF/FP 1882, 17 [8], KSA 9.667 (= Versuche, op. cit., p. 12): "O artista tem o poder de fazer acordar a força de agir que dorme em nossas almas".

32 Cf. a carta a Overbeck de 6 de dezembro de 1883 / KSB 6. 460-461.

40 | Cad. Nietzsche, Guarulhos/Porto Seguro, v.42, n.3, p. 17-44, setembro/dezembro, 2021. 
constituir para si uma genealogia filosófica em que se encontram todas as nobrezas da história. Se essa heráldica tem aliados e inimigos, em compensação ela não reproduz o gesto do homem vulgar, que não sabe reconhecer a grandeza de seus antípodas (é que ele não sabe reconhecer o antípoda enquanto tal). Num texto capital, Nietzsche admite assim, sem desvio ou dissuasão, que sua heráldica pessoal mais não é do que a grande saúde do sentido histórico, o que certamente autoriza a compreender o conjunto da abordagem nietzschiana como uma automitridização do sentido histórico - depois de tudo, tratavase bem de compará-lo, de acordo com a Segunda extemporânea, a um escorpião que faz voltar seu ferrão contra si mesmo. Mas entre 1874 e 1881, esse envenenamento teve por efeito paradoxal o de sanar, até que possam brotar de novo novos rebentos, festejando suas dionisíacas (amor fati), isto é, sua nova florescência:

A ciência nos dá nossa árvore genealógica de nobleza, nossa heráldica. Ela nos dá ancestrais. (...) O sentido histórico é isso que há de novo, ali algo de realmente grande está crescendo! De início nocivo, como tudo o que é novo! É preciso longamente se aclimatar, antes de sanear e de fazer brotar uma grande floração! Ouvimos falar de tudo isso que possuíam nossos ancestrais - os heróis -, é-nos necessário renunciar a muita coisa, mas compensar toda perda com as mais elevadas aquisições (NF/FP 1881, 12 [76], KSA 9.590).

Ressurreição? Palingenesia? Pode ser. Mas naturalmente não é a da carne do Cristo, Pelo contrário: o novo sentido histórico recompõe o corpo eterno de Dioniso, do qual os membros foram espalhados pelo tempo apolíneo da história humana.

À luz do conjunto dessas observações, parece que o perspectivismo designa uma Erlebnis, um vivido hierarquizado de perspectivas históricas, e correlativamente um ethos disposto a dominar perspectivas presentes e passadas para hierarquizá-las a serviço de um objetivo novo. Esse domínio de perspectivas exige que se lhes tenha habitado do interior, de as ter vivido: chame-se a isso 
Sorosina, A.

de potência de síntese, força plástica ou grande saúde, essa atividade designa a intensidade da vida que assimilou outras perspectivas, a penetração do olhar daquele que viveu e ultrapassou numerosas perspectivas, reatualizando a vontade de potência encaracolada num passado que jamais passou. É ainda em Emerson que Nietzsche encontra a fórmula mais lapidar: "A história é o absurdo e a injúria tão logo ela pretende ser mais do que divertida narração e parábola de meu ser e de meu devir. - Lançando um olhar para trás, ele se lamenta sobre o passado ou bem se põe na ponta dos pés, esperando espiar alguma coisa do porvir. Mas deveria viver com a natureza no presente, acima do tempo (NF/FP 1882, 17 [34] / KSA 9, 671)."

Nietzsche sabia bem que suas próprias perspectivas, desse ponto de vista, estavam destinadas a revestir o sentido de uma função para outras perspectivas futuras, ele que escrevia ainda em seus cadernos lendo Emerson: "Suponha que meu livro só existisse na cabeça dos homens, tudo num certo sentido seria extraído tão-só de seus pensamentos e de seu ser - seria uma "soma de relações". Significa que não seria mais do que isso? (...) Que uma coisa se resolve em uma soma de relações não prova nada contra a sua realidade (NF/ FP 1881, 13[11], KSA 9. 620)."

Não será isso, por fim, o que caracteriza o gesto que nós realizamos, nós leitores e comentadores de Nietzsche, ao que estabelecemos relações entre seus textos e preenchemos as lacunas que os separam? Nossa heráldica é a dos ridículos pretendentes, porta-vozes de um novo evangelho, ou a dos arautos alegremente insolentes, que ao ruminar não apresentam ao fim mais que uma perspectiva digerida do perspectivismo de Nietzsche? Assim fazendo nós extrapolamos e forjamos uma imagem desses filosofemas, que por fim mais não é do que a nossa. Nisso não há nada de lamentável, sem dúvida: nós realizamos em ato o perspectivismo ao caminhar singularmente pelos textos, estabelecendo reações e lhes conferindo o sentido de uma função para nós; nós ensinamos o dossiê do perspectivismo ao serviço da interpretação que julgamos a mais

42 | Cad. Nietzsche, Guarulhos/Porto Seguro, v.42, n.3, p. 17-44, setembro/dezembro, 2021. 
fecunda. E isso nada prova contra nossas interpretações, se Nietzsche tem razão em sugerir que é a riqueza de relações, e o perpétuo relançar de sua articulação por comentários, que define a sua profundidade com a condição de que ela intensifique o sentimento de nossa vitalidade.

\title{
The names of history seen in perspective: Nietzsche, Emerson and Roux
}

\begin{abstract}
Nietzsche's thought leads him to elaborate the concept of will to power and the idea of perspectivism, even his the word doesn't appear, yet, in his writings. We show that the idea of a perspectival view of several idiosyncratic conceptions is the heart of Nietzsche's conception of perspectivism, insofar as he is both interested in the nature of history, confronting himself to Emerson, and in the nature of evolution, when he discovers Wilhelm Roux.
\end{abstract}

Keywords: perspectivism, history, evolution, digestion, humanity, future.

\section{Referências}

GERHARDT, V. Vom Willen zum Macht. Berlin: De Gruyter, 1996.

EMERSON, R. W. Essais II, trad. Ch. Fournier. Paris: Michel Houdiard, 2005.

FOUCAULT, M. "Michel Foucault, 'Les Mots et les Choses"” in Dits et écrits I. Paris: Gallimard, 2001.

MÜLLER-LAUTER, W. "Der Organismus als innerer Kampf: der Einfluß von Wilhelm Roux auf Friedrich Nietzsche”. In: Nietzsche-Studien 7, 1978, p. 189-223. 
Sorosina, A.

NIETZSCHE, F. W. Sämtliche Werke. Kritische Studienausgabe (KSA), 15 vols. (Organizada por Giorgio Colli e Mazzino Montinari), Berlim: Walter de Gruyter \& Co., 1988.

. Sämtliche Briefe: Kritische Studienausgabe (KSB), 8 Vols. (Organizada por Giorgio Colli e Mazzino Montinari ). Berlim: Walter de Gruyter \& Co., 1986.

ORSUCCI, A. Dalla biologia cellulare alle scienze dello spirito. Bologna: Il mulino, 1992, p. 192-202.

ROUX, W. Der Kampf der Theile im Organismus, Leipzig, Engelmann, 1881 [BN].

STINGELIN, M. "Nietzsche und die Biologie - neue quellenkundliche Studien". In: Nietzsche-Studien 32, 2003, p. 503-513.

Enviado: 15/06/2021

Aceito: 21/08/2021

44 | Cad. Nietzsche, Guarulhos/Porto Seguro, v.42, n.3, p. 17-44, setembro/dezembro, 2021. 